\title{
Standardizing Methods for Evaluating the Chilling Requirements to Break Dormancy in Seeds and Buds (Including Geophytes)
}

\author{
held at \\ 97th ASHS Annual Conference
}

24 July 2000

Orlando, Fla.

\author{
sponsored by the \\ Plant Dormancy Research Working Group \\ Seed Research Working Group \\ Floriculture Working Group \\ published by the \\ American Society for Horticultural Science \\ Alexandria, VA 22314-2851
}

as a special insert in

HortScience 38(3), June 2003 